Research Article

\title{
Finite Element Modeling for the Antivibration Pavement Used to Improve the Slope Stability of the Open-Pit Mine
}

\author{
Jiandong Huang, ${ }^{1,2}$ Tianhong Duan $\mathbb{D D}^{1,2}$ Yawei Lei, ${ }^{3}$ and Mahdi Hasanipanah ${ }^{4}$ \\ ${ }^{1}$ State Key Laboratory of Coal Resources and Safe Mining, China University of Mining and Technology, Xuzhou 221116, China \\ ${ }^{2}$ School of Mines, China University of Mining and Technology, Xuzhou 221116, China \\ ${ }^{3}$ China Construction Second Engineering Bureau Ltd., Beijing 100160, China \\ ${ }^{4}$ Institute of Research and Development, Duy Tan University, Da Nang 550000, Vietnam \\ Correspondence should be addressed to Tianhong Duan; passionduan@cumt.edu.cn
}

Received 17 November 2020; Revised 26 November 2020; Accepted 29 November 2020; Published 9 December 2020

Academic Editor: Junfei Zhang

Copyright (c) 2020 Jiandong Huang et al. This is an open access article distributed under the Creative Commons Attribution License, which permits unrestricted use, distribution, and reproduction in any medium, provided the original work is properly cited.

\begin{abstract}
Vibrations induced by traffic are of concern for the slope stability of the open-pit mine. Different solutions to mitigate this phenomenon are under investigation. In the field of pavement engineering, the so-called antivibration paving technologies are under investigation in order to avoid the generation of excessive vibration and contains propagation. To more fully examine the effectiveness and potential of the antivibration pavement in the application of vibration absorbing for the open-pit mines, numerical simulations based on a two-dimensional (2D) finite element (FE) model were conducted. Sensitivity analysis of varying monitored points and varying loads are performed. Several important parameters such as the damping layer position and thickness and damping ratio are evaluated as well. By using this FE simulation to model the vibration response induced by traffic, the costly construction mistakes and field experimentation can be avoided.
\end{abstract}

\section{Introduction and Background}

Open-pit mining is the most important technology for extracting mineral resources from the Earth's crust [1-7]. Production rates of open pits have progressively grown over the last 100 years and they will continue growing in the future [5-11]. The ultimate slopes of an open-pit mine are generally excavated to the steepest possible angle, as the economic consequences of the excavation angle are significant; for instance, for large scale open pits, changes in slope angle by approximately $2-3^{\circ}$ can be measured in hundreds of millions of dollars in project value $[3,12]$. Steeper slope angles, however, result in an increased risk of slope failure, the consequences of which affect mining operations [4]. Consequently, continual evaluation of the stability of excavated slopes is a vital component of open-pit design and operation. Traffic-induced vibrations around the open-pit mine can also be a significant factor concerning the slope stability [13-15]. It can cause the occurrence of a landslide that is a serious life threat for people working at the slopes of the open-pit mine. Due to the complexity and uncertainties of the landslide formation and causing factors, the landslide surveillances and predictions are always highly paid attention to by international researchers [16-22]. To mitigate the effects of traffic-induced vibration on the slope stability of the mining areas, various preventive strategies are under investigation. Limiting traffic volumes and speed, screening of vibration by using in-ground barriers, and developing isolation systems represent some of the methods proposed [23]. In the field of pavement engineering, the so-called antivibration paving technology is under investigation to avoid the generation of excessive vibration and contains propagation [24]. To preserve an ancient building (the Villa Farnesina, Roma) against traffic-induced vibrations, an antivibration system composed of a concrete grid supported by rubber pads was developed under the near Lungotevere road, reducing the acceleration values of about $80 \%$ according to the obtained results. Similar solutions have also 
been used for new constructions in Piazzetta S. Paolo, Milan, and Via Parigi, Roma [25]. The antivibration pavement has also been developed by Dondi et al. and Grandi with a lowerstiffness vibration-absorbing layer which did not reduce the stiffness of the whole pavement systems [26, 27]. It has been proved to increase the elastic absorption capacity of the vibrations caused by the surface irregularities near the source. Based on the optimized surface texture as well as the improvement of the vibration absorbing, another antivibration pavement was constructed for the Municipality of Novara as well [24]. The verification is conducted by the vibration comparison of the antivibration pavement and one reference, showing the antivibration level reached. Besides, according to the study by Hanazato et al. [28], the increase in damping of pavement materials can reduce ground vibrations into the loading area and within the corresponding surrounding region. This improvement is critical for reducing vibrations to improve the quality of life and to preserve the stability of buildings [29].

These experimental and field observations indicated that the antivibration pavement is a viable and attractive solution to prevent the damage caused by the traffic induced vibration. By using the dynamic analysis in pavement engineering, the determination of in-site dynamic properties of paving materials is fundamental to accurately predict the mechanical response of the road structure as well as the wave propagation transferring into the places at specific distances from the loading area [30-34]. However, so far, there is no research aimed at the application of antivibration pavement in open-pit mines, requiring high slope stability. To fully examine the effectiveness and potential of the antivibration pavement to be applied for the open-pit mines, the study presented in this paper involved the creation and analysis of a two-dimensional (2D) finite element (FE) model of the antivibration pavement based on the field tests. The FE model was subjected to a haversine pulse load representing the passage of traffic. Parametric studies were conducted based on varying damping layer position and thicknesses as well as damping ratios. Sensitivity analyses were also performed by varying loading times as well as varying monitored points. Through these predictive simulations, expensive and cumbersome field tests can be avoided. On the other hand, the conclusions obtained by the simulation can provide the corresponding criteria for the development of future experiments.

\section{Research Objective and Aims}

The main purpose of the present study is to evaluate the potential of laying the antivibration pavement around the open-pit mine as well as the effects on vibration reduction and slope stability. The detailed research objectives are as follows.

(1) To establish a reliable FE model based on the corresponding experimental tests and field measurements. The elements (model size, mesh, element type, and analysis method) used to construct the FE model should be optimized.
(2) To analyze the sensitivities of varying traffic loading on the slope stability of the open-pit mines.

(3) To evaluate the effects of varying design parameters (damping layer position, damping layer thickness, and damping properties) of the antivibration on the slope stability of the open-pit mines.

\section{Finite Element (FE) Simulations}

For this study, the traffic-induced vibration of the pavement with a special damping layer was simulated using the widely used FE program ABAQUS. The schematic diagram of the FE simulation is given in Figure 1. The FE model represents a cross-section of a typical pavement structure, the open-pit mine area as well as the safe distance from the mining slope to the pavement structure.

This is a two-dimensional (2D) simplification of the field problem. The pavement structure consists of an asphalt concrete (AC) layer, a layer of subbase, and a layer of subgrade by the compacted soil, and the safe distance from the mining slope is characterized by the uncompacted soil. The 4-node bilinear axisymmetric quadrilateral and reduced integration element, CAX4R, are selected as a mesh element type to improve the calculation accuracy and to reduce calculation time. The FE model is meshed by refining the loading and upper areas as well as roughening the remaining ones [35]. Those physical parameters including model size and mesh size based on the convergence optimization are performed as well. The mechanical properties of the materials for the pavements and safe distance from the mining slope are listed in Table 1 [36-38]. The time-domain analysis was selected to perform the simulation. The time step length was determined as $0.01 \mathrm{~s}$ to reduce the calculation time and total simulation time equaled $0.1 \mathrm{~s}$.

The FE simulation based on the developed method is established in order to compare the dynamic response with in-situ experimental tests of falling weight deflectometer (FWD), which is a widely used nondestructive test for flexible pavement evaluation and assessment of residual life. The FWD (Figure 2) applies an impact load to the pavement surface and to simulate the action of traffic, and the pavement response in terms of deflections is measured at several radial locations from the load center. In order to examine the applicability of the proposed method, the in-situ measurements including nonrubberized and rubberized asphalt pavement were carried out. The thickness, elastic modulus, and Poisson ratio of each layer are back-calculated from the field FWD tests while the elastic modulus of the damping layer is determined according to the laboratory results by the means of dynamic modulus and phase angle evaluation (AASHTO TP 79-12) as mentioned above.

The damping layer is placed at $0,5 \mathrm{~cm}, 10 \mathrm{~cm}, 15 \mathrm{~cm}$, and $20 \mathrm{~cm}$ from the top to evaluate the effect of damping layer position on vibration attenuation. The effect of the damping thickness is evaluated with values of $0,1,2$, and $3 \mathrm{~cm}$. The damping ratio of the damping layer varies by $0.02,0.05,0.1$, 0.15 , and 0.2 . The Rayleigh damping is used for the damping effect characterization according to the method proposed by Huang and Sun [38]. The haversine pulse load is applied on a 


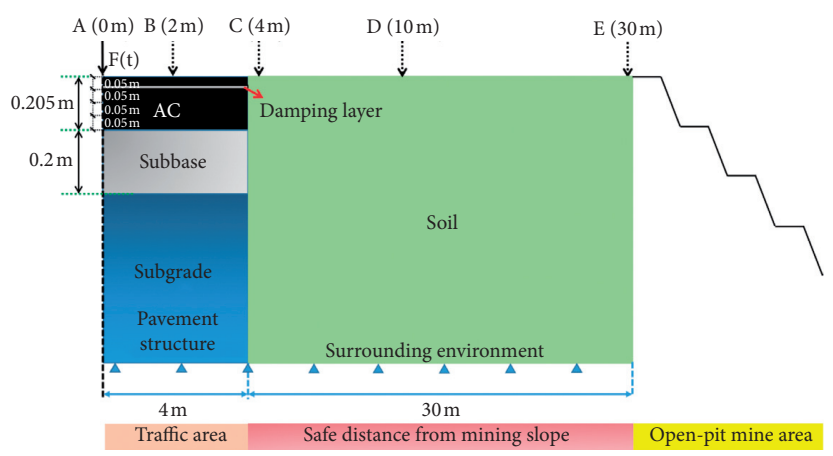

FIgURE 1: Schematic diagram of the finite element (FE) simulation.

TABLE 1: Mechanical properties used for the FE simulations.

\begin{tabular}{|c|c|c|c|c|c|c|c|}
\hline & uctures & Materials & Thickness $(\mathrm{cm})$ & $\begin{array}{c}\text { Elastic } \\
\text { modulus (MPa) }\end{array}$ & $\begin{array}{c}\text { Poisson } \\
\text { ratio }\end{array}$ & $\begin{array}{c}\text { Damping } \\
\text { ratio }\end{array}$ & Density $\left(\mathrm{Kg} / \mathrm{m}^{3}\right)$ \\
\hline \multirow{3}{*}{ Pavement } & Surface layer & $\mathrm{AC}$ & 20.5 & 5680 & 0.3 & 0.05 & 2400 \\
\hline & Subbase layer & Gravel & 22.5 & 660 & 0.3 & 0.02 & 2000 \\
\hline & Subgrade & Compacted soil & - & 110 & 0.35 & 0.02 & 1500 \\
\hline \multirow{2}{*}{\multicolumn{2}{|c|}{$\begin{array}{l}\text { Damping layer } \\
\text { Safe distance from } \\
\text { mining slope }\end{array}$}} & RMAC & $0,1,2,3$ & 850 & 0.3 & $0.02,0.05,0.1,0.15,0.2$ & 2400 \\
\hline & & Uncompacted soil & - & 110 & 0.35 & 0.02 & 1500 \\
\hline
\end{tabular}

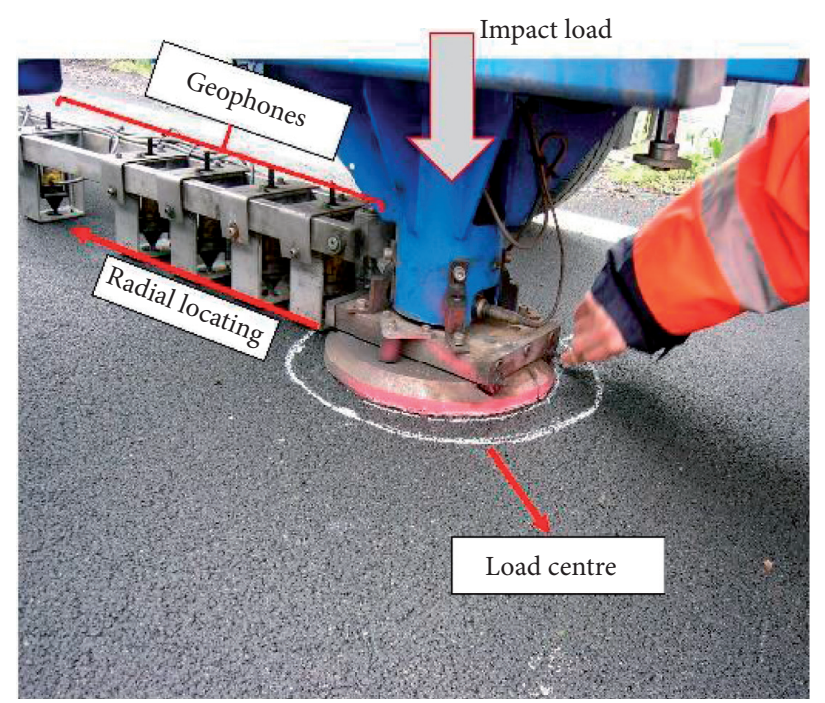

Figure 2: Experimental test of FWD.

circular footprint with a radius of $0.15 \mathrm{~m}$ and it is the idealized representation of the dynamic loading applied by the passage of traffic, which is also recognized as the load subjected to falling weight deflectometer (FWD) tests. The magnitude of the load is determined as $800 \mathrm{kPa}$, representing the axle loading of the passing traffic. Five points including point $\mathrm{A}$, on the pavement directly underneath the loading and points $\mathrm{B}, \mathrm{C}, \mathrm{D}$, and $\mathrm{E}$, which are $2,4,10$, and $30 \mathrm{~m}$ away from the loading, are monitored for their time histories of accelerations during the simulations.

The slope stability of the open-pit mine is monitored by determining the vibration at the boundary of the mining area. The root-mean-square acceleration $\left(A_{\mathrm{RMS}}\right)$ recorded at the five monitored points closely for evaluation of vibration reduction and it is given by

$$
A_{\mathrm{RMS}}=\sqrt{\frac{1}{T} \int_{0}^{T} a^{2}(t) \mathrm{d} t},
$$

where $a(t)$ is the acceleration at time $t$ and $T$ is the duration of vibration. The root mean square (RMS) refers to a common mathematical method of defining the effective magnitude. For a uniform sine wave, the root-meansquare value is 0.707 times the peak value or 0.354 times 
the peak-to-peak value. By comparing the root-meansquare and peak accelerations of monitored points, the capacity of the damping layer in the vibration reduction can then be determined for the evaluation of the slope stability of the open-pit mine.

\section{Results and Analysis}

4.1. Sensitive Analysis of Varying Monitored Points on Slope Stability. Vibration reduction at different monitored points can be different. In this section, when the damping layer with a thickness of $30 \mathrm{~mm}$ is at the bottom and top of the asphalt concrete (AC) layer, the influences of varying monitored points on vibration reduction is evaluated. The vibration reduction is determined as follows. When the damping ratio of the damping layer change from 0.02 to 0.2 , the RMS accelerations at the monitored point are recorded as $A_{\mathrm{RMS}}$ ( $\xi=0.02)$ and $A_{\mathrm{RMS}}(\xi=0.2)$, respectively. Then the vibration reduction, $\Delta_{\text {vibration }}$, can be presented as

$$
\Delta_{\text {vibration }}=\frac{A_{\mathrm{RMS}}(\xi=0.02)-A_{\mathrm{RMS}}(\xi=0.2)}{A_{\mathrm{RMS}}(\xi=0.02)},
$$

by which $\Delta_{\text {vibration }}$ at the five monitored points A, B, C, D, and $E$ are recorded. Figure 3 presents the relationship between distance (from the monitored point to the loading point) and $\Delta_{\text {vibration }}$ when the damping layer is placed at the top and bottom of the AC.

A relative higher vibration reduction of $15 \%$ is observed when the monitored point is approximately $2 \mathrm{~m}$ to $30 \mathrm{~m}$ away from the loading point. With the increase of distance, the vibration reduction increases firstly and then decreases. The maximum value appears at a distance of 5-6 $\mathrm{m}$. Also, regardless of whether the damping layer is at the top or the bottom of the asphalt layer, similar results can be obtained. When the loading point is also the monitored point, the minimum vibration reduction appears. The loading point is on the pavement, where the vibration response much depends on the stiffness and mass characteristics instead of the damping characteristics. The damping ratio changes from 0.02 to 0.2 while the other parameters related to the stiffness and mass characteristics stay the same. Hence, minor displacement and phase difference can be obtained, resulting in a minor reduction of $A_{\mathrm{RMS}}$. When the distance from the monitored point to the loading point increases, the damping effect of the damping layer plays a predominant role; thus the gradually obvious reduction of $A_{\mathrm{RMS}}$ can be found. However, with the continuous increase in distance, the damping effect of the surrounding soil starts to play the predominant role, causing the reduction of $\Delta_{\text {vibration. }}$ It can be predicted when the distance is far enough, $\Delta_{\text {vibration }}$ may decrease until it vanishes. It should be noted that traffic should typically be kept at a safe distance of about 30 meters from the open-pit slope. From the above research results, a $15 \%$ reduction in vibration is of great significance for maintaining the stability of open-pit mining slopes.

4.2. Sensitive Analysis of Varying Traffic Loads on Slope Stability. As a special dynamic structure, the pavement may vibrate differently with varying loads. Therefore, the slope stability of the open-pit mines should be analyzed for the corresponding loads. In the present study, three haversine pulse loads (which can represent the conventional traffic loads) with loading times of $24 \mathrm{~ms}, 36 \mathrm{~ms}$, and $96 \mathrm{~ms}$ are applied, as shown in Figure 4.

These three haversine pulse loads can represent the conventional traffic loads. Actually, the relationship between the loading times and actual traffic speed can be described by the following equation:

$$
h=\frac{12 a}{s}
$$

where $h$ is the loading time (s), a is the loading radius (m), and $s$ is the traffic speed $(\mathrm{m} / \mathrm{s})$. When the damping layer is at the bottom of the AC layer, the results of vibration reduction for varying loads are presented in Figure 5.

For different loading times, the maximum vibration reduction appears at different distances. For the loading time of $36 \mathrm{~ms}$, the maximum vibration reduction is observed at $5 \mathrm{~m}$ away from the loading point and a relatively higher $\Delta_{\text {vibration }}$ can be obtained, while, for the loading times of $24 \mathrm{~ms}$ and $90 \mathrm{~ms}$, the maximum vibration reductions appear at approximate $10 \mathrm{~m}$ away from the loading point. However, in any case, the three loads show very similar trends, demonstrating that the dynamic response of such pavement structure is not sensitive to the pulse loads with loading times in the range of $24 \mathrm{~ms}$ to $90 \mathrm{~ms}$. Therefore, it is evident that the antivibration pavement can maintain the slope stability of the open-pit mine under varying traffic speeds.

\subsection{Effect of Damping Properties on the Slope Stability.} Five damping ratios are selected to determine their effects on the vibration response of the pavement structure. The simulation results of $A_{\mathrm{RMS}}$ (when the damping layer thickness is $10 \mathrm{~mm}$ ) at monitored point A with varying damping ratios are shown in Figure 6. The damping layer positions are given in the legend.

With the increase of the damping ratio, $A_{\mathrm{RMS}}$ decrease with obvious linearity. This may be explained that, compared to other layers (AC layer, subbase layer, and subgrade), the damping layer plays a predominant role in characterizing the vibration-reduction effect, causing $\Delta_{\text {vibration }}$ of the whole system strong linearity with the damping ratio. It is worth noting that here the damping layer is playing a predominant role in the damping characteristics of the entire system, instead of the dynamic response, which mainly depends on the mass matrix and stiffness matrix.

Figure 7 presents the simulation results of $A_{\mathrm{RMS}}$ at point A when the damping layer thickness is $30 \mathrm{~mm}$.

Similar results are obtained compared to those obtained when the thickness is $10 \mathrm{~mm}$, demonstrating the linear reduction of $A_{\mathrm{RMS}}$ can still be applicable for different damping layer thickness. In such a linear relationship, the slope of $A_{\mathrm{RMS}}$ curve represents the effect of varying damping ratios. A higher slope value, demonstrating the more obvious effect of vibration reduction, is more preferable during the process of optimizing the damping ratio. Unfortunately, all $A_{\mathrm{RMS}}$ show closed slope values from Figures 6 and 7, though a little 


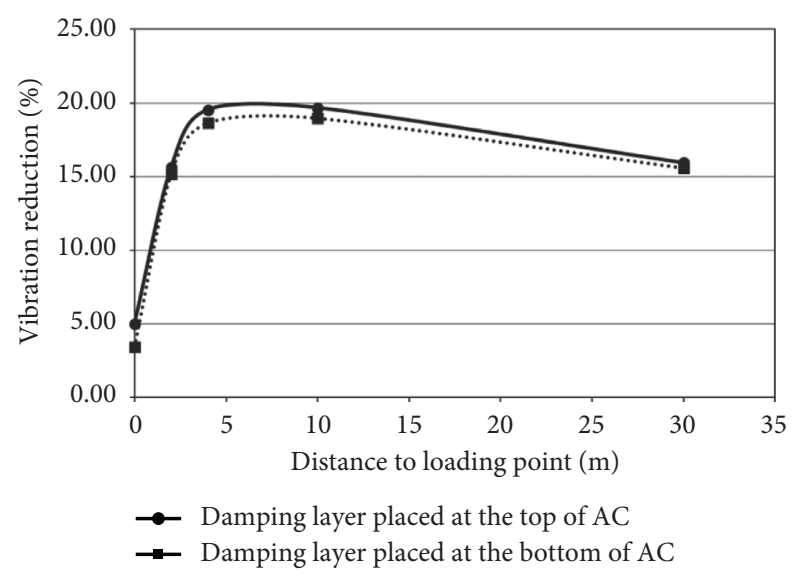

FIgURE 3: The relationship between the monitored points and vibration reduction.

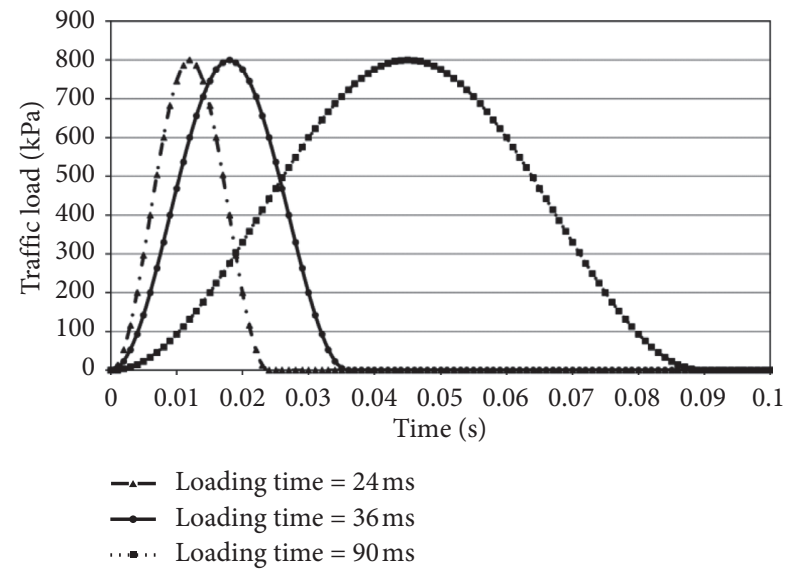

FIgURE 4: The loads applied in the simulations.

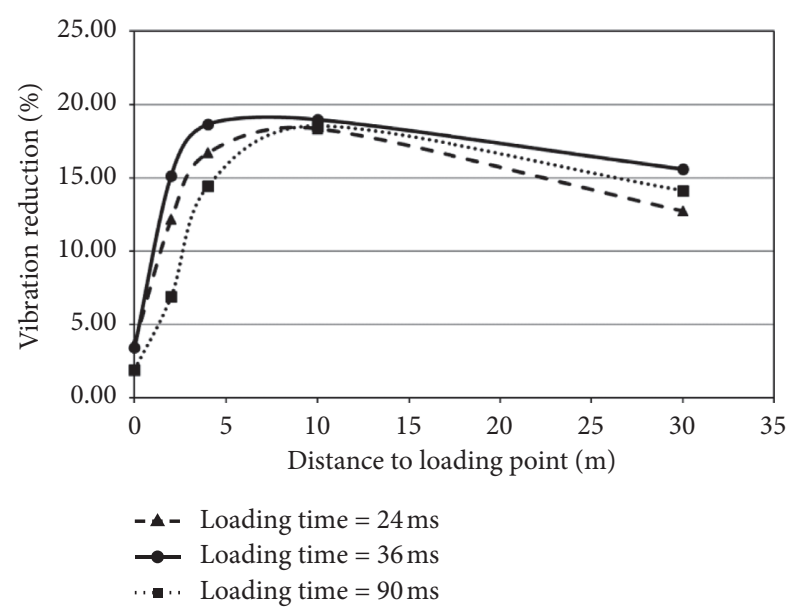

FIGURE 5: Sensitive analysis for varying traffic loads.

higher slope value when the damping layer is $0 \mathrm{~cm}$ from the top, by which bare practical significance can be supported.

Figures 8 and 9 are the effects of damping ratios at point $\mathrm{E}$ when the damping layer thicknesses are $10 \mathrm{~mm}$ and $30 \mathrm{~mm}$, respectively.

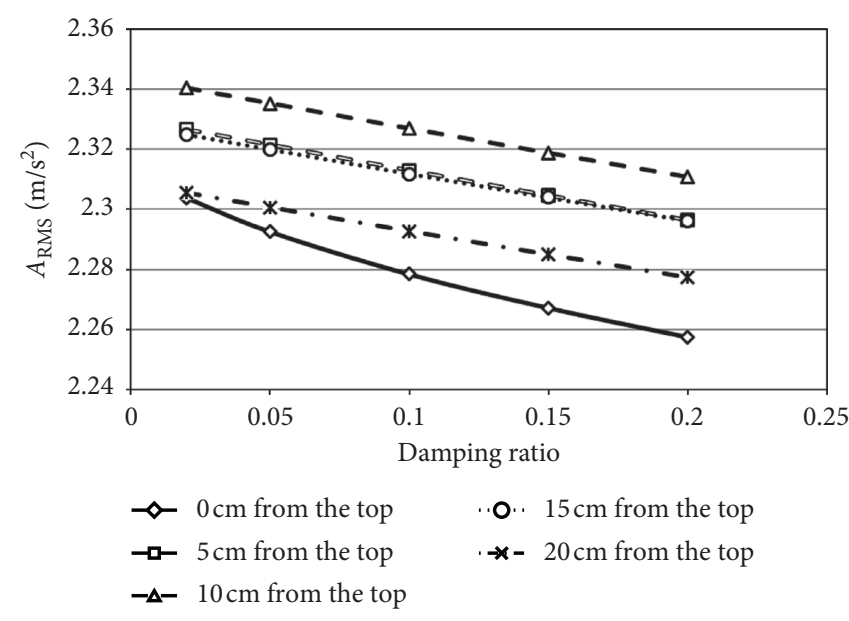

FIgURE 6: The effects of the damping ratio on vibration reduction (at monitored point $\mathrm{A}$; damping layer thickness $=10 \mathrm{~mm}$ ).

A similar linear relationship between damping ratio and $A_{\mathrm{RMS}}$ can also be found at monitored point E. When the damping layer thickness is $30 \mathrm{~mm}$ and the damping ratio changes from 0.02 to 0.2 , the vibration at $10 \mathrm{~m}$ and $30 \mathrm{~m}$ away from the pavement can reduce about $20 \%$ and $15 \%$, respectively. Such reductions can demonstrate the significant benefits of the damping layer in reducing the impact of traffic-induced vibrations on the surrounding environment and building.

The damping property of the asphaltic material is highly dependent upon the environmental conditions to which they are exposed. As loading time and temperatures change, the damping ratio will vary even if the same boundary condition. However, according to the viscoelastic property of the asphaltic materials, the intrinsic material damping at the same condition of temperature, load, and boundary condition can be roughly compared. Particularly, for the pavement structure with normal temperature and load, the damping ratios of soil, conventional asphalt mix, and rubberized asphalt mixture can be regarded as $0.02,0.05$, and 0.1 , respectively. Hence, in order to obtain the obvious vibration reduction effect, the damping ratio of damping asphalt mixtures special for the damping layer should arrive at $0.15-0.2$, which is almost 2 times compared to conventional rubberized mix under the same loading condition, while from the laboratory results obtained, such design target has already arrived $[37,38]$.

4.4. Effect of the Damping Layer Thickness. Another very essential design parameter for the antivibration pavement is the damping layer thickness. In this series of simulations, the thickness of the damping layer varies between $0 \mathrm{~mm}, 10 \mathrm{~mm}$, $20 \mathrm{~mm}$, and $30 \mathrm{~mm}$. The effect of damping layer thickness at monitored point $\mathrm{A}$ is shown in Figure 10.

The increasing thickness of the damping layer does not necessarily reduce the vibration response at point A. For example, as the damping layer is $5 \mathrm{~cm}$ from the top, with the increased thickness, the vibration can show the trend of increase for $\xi=0.02$ or 0.05 , demonstrating that the 


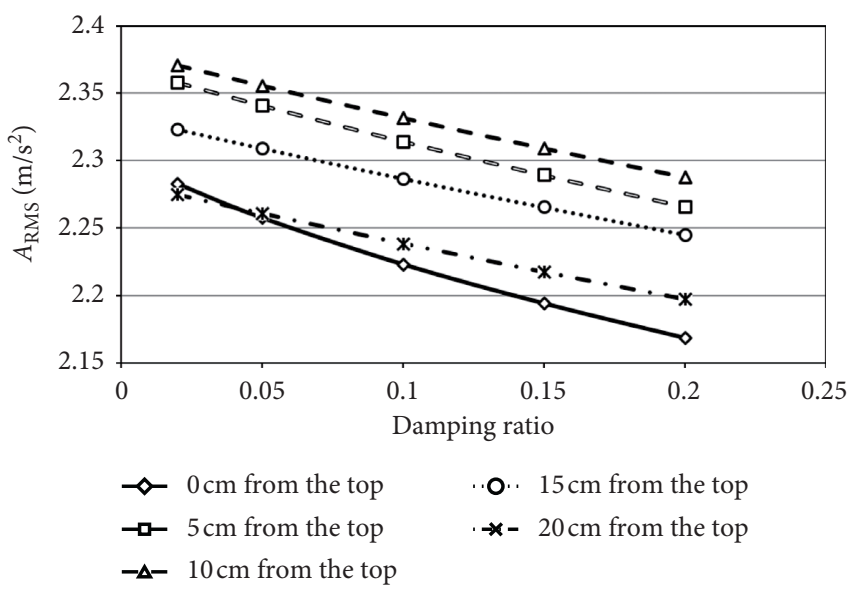

Figure 7: The effects of the damping ratio on vibration reduction (at monitored point A; damping layer thickness $=30 \mathrm{~mm}$ ).

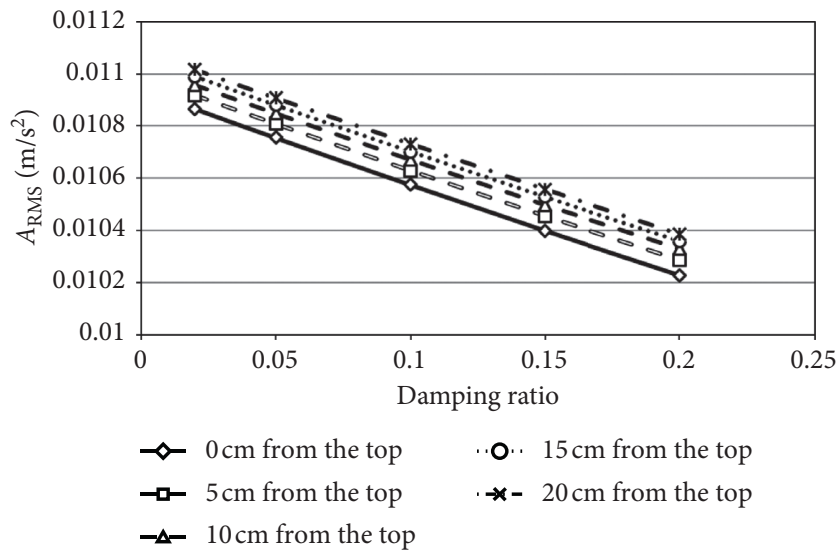

Figure 8: The effects of the damping ratio on vibration reduction (at monitored point E; damping layer thickness $=10 \mathrm{~mm}$ ).

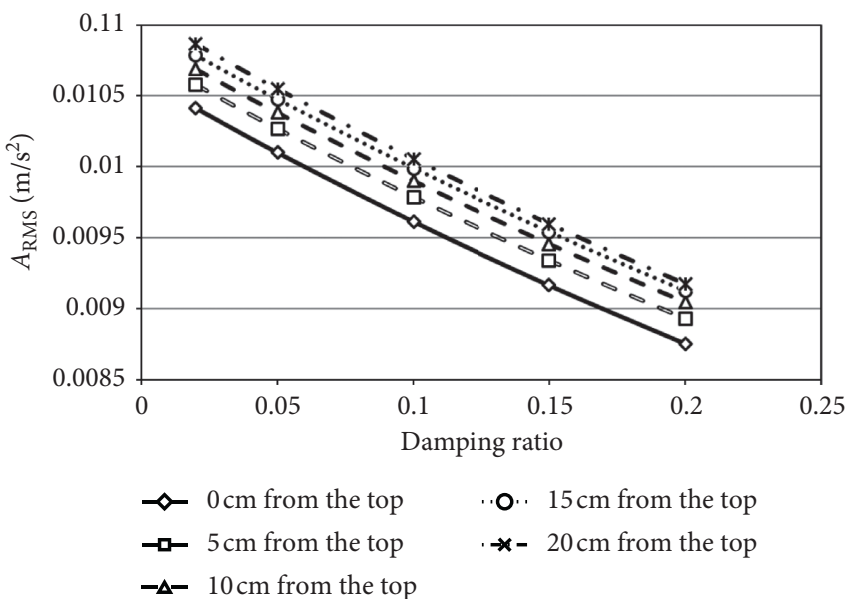

Figure 9: The effects of the damping ratio on vibration reduction (at monitored point E; damping layer thickness $=30 \mathrm{~mm}$ ).

increasing thickness of the damping layer may have a negative effect as the damping ratio is low. This can be due to the lower elastic modulus of the damping asphalt mixtures, composed by which the thicker layer can result in a higher vibration under the same load. However, such a negative effect can occur only when the monitoring point is point
A. Considering the vibration reductions at monitored points E (see Figure 11), positive effects caused by the increased thickness can always be found.

In addition, the reductions are almost linear for all thicknesses, from which the optimized thickness of the damping layer cannot be obtained directly. However, based 

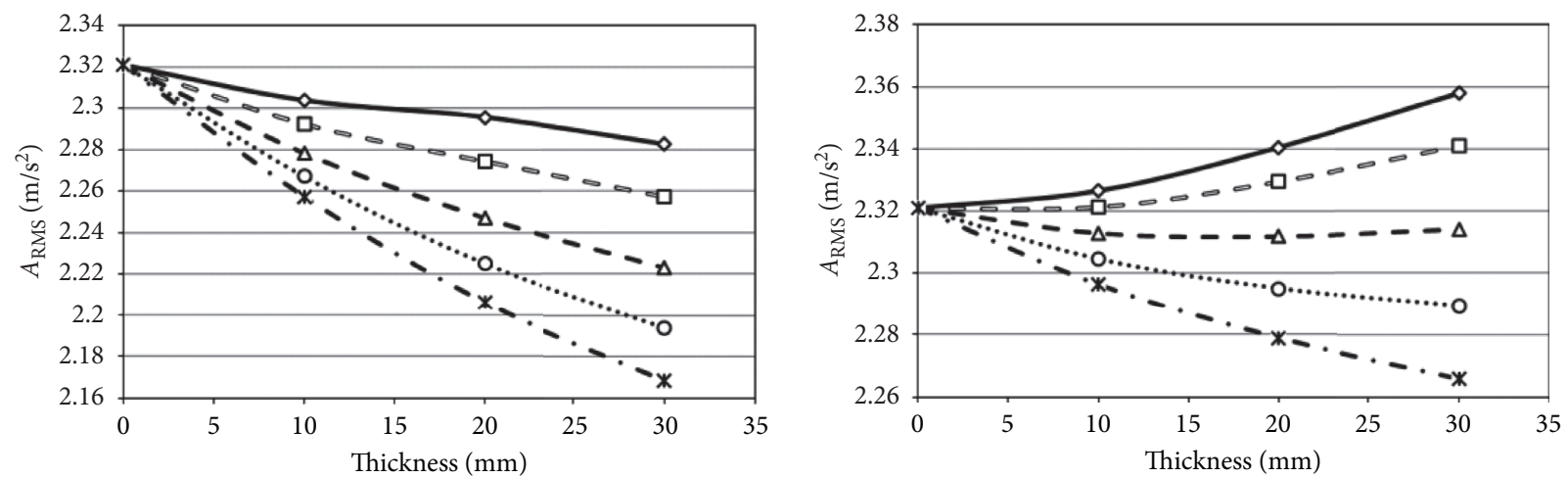
$\prec \quad \xi=0.02$
$\rightarrow-\xi=0.05$
$-\Delta-\xi=0.1$

$$
\begin{aligned}
\text {.0. } \quad \xi=0.15 \\
-\times-\quad \xi=0.2
\end{aligned}
$$

(a)

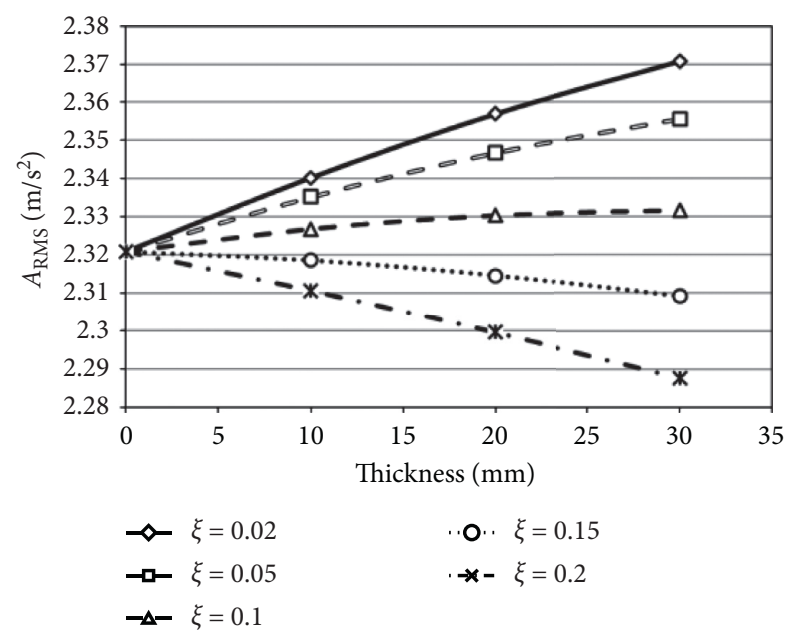

(c)
$\leadsto \quad \xi=0.02$
$\neg-\xi=0.05$
. . . $\xi=0.15$
$-\Delta-\quad \xi=0.1$

(b)
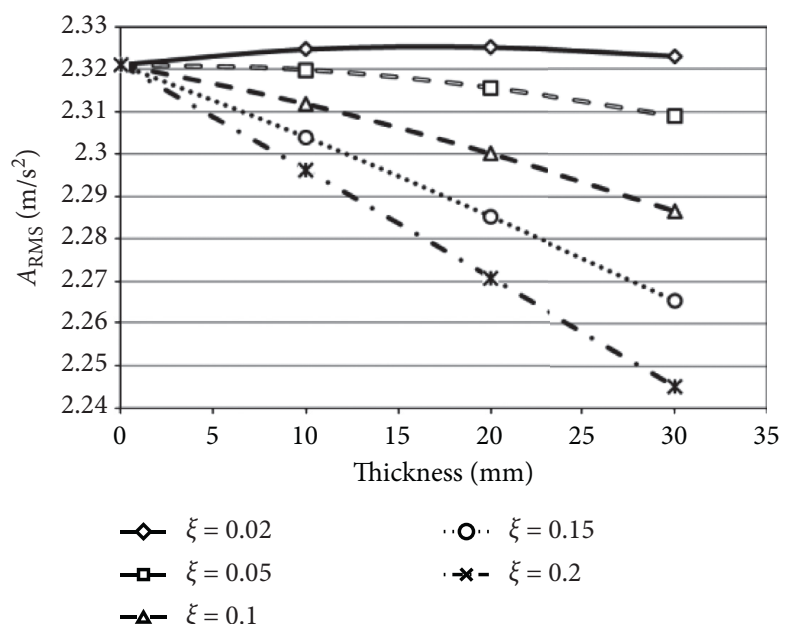

(d)

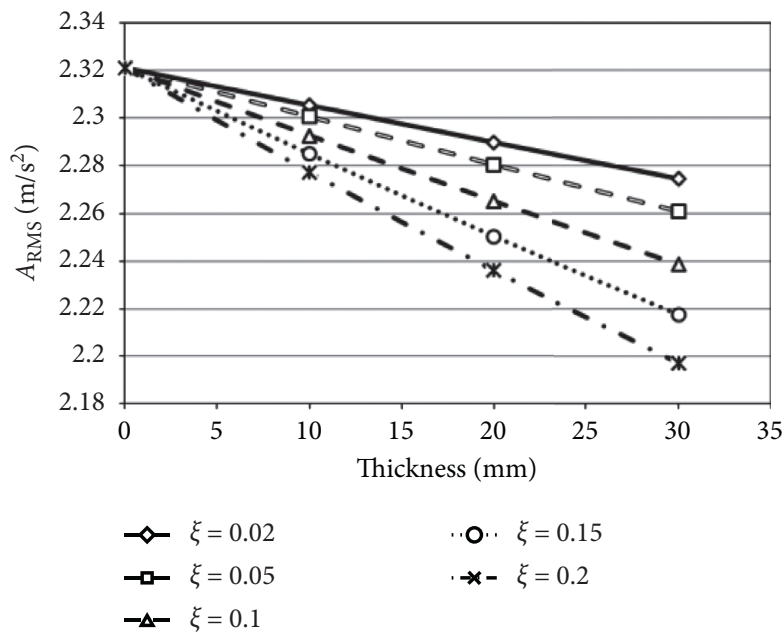

(e)

Figure 10: The effects of damping thickness at monitored point A. (a) $0 \mathrm{~cm}$ from the top. (b) $5 \mathrm{~cm}$ from the top. (c) $10 \mathrm{~cm}$ from the top. (d) $15 \mathrm{~cm}$ from the top. (e) $20 \mathrm{~cm}$ from the top.

on the consideration of construction cost and pavement structure reliability, $30 \mathrm{~mm}$ can be regarded as the optimized thickness.
4.5. Effect of the Damping Layer Position. When the thickness of the damping layer is $30 \mathrm{~mm}$, the effects of the damping layer position on $A_{\mathrm{RMS}}$ at monitored points $\mathrm{A}, \mathrm{C}$, and $\mathrm{E}$ are 

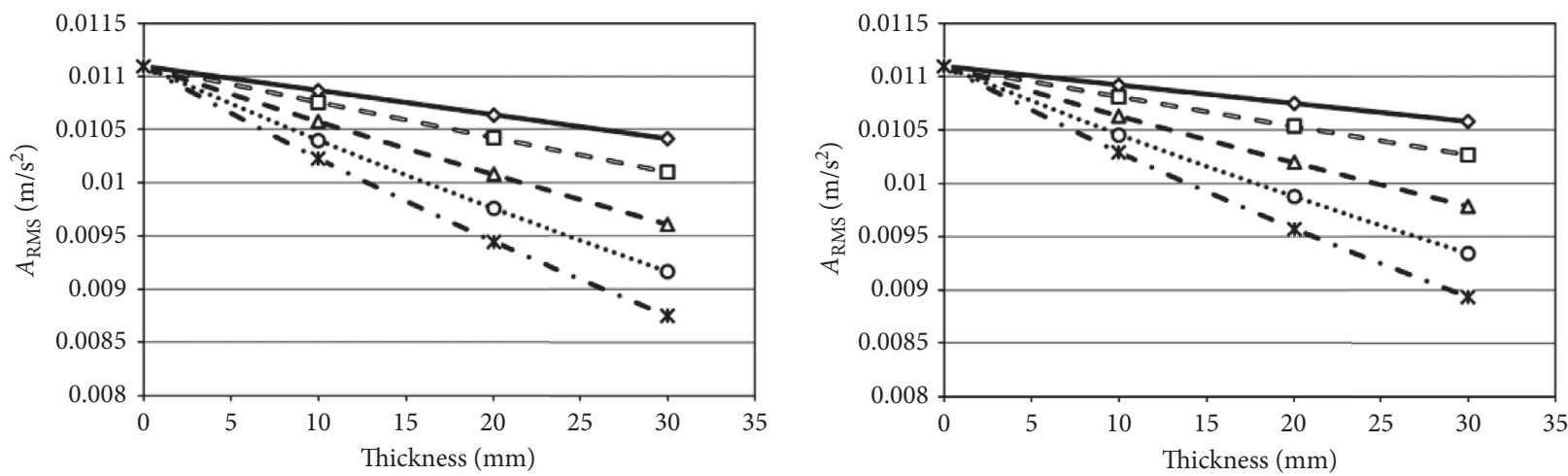

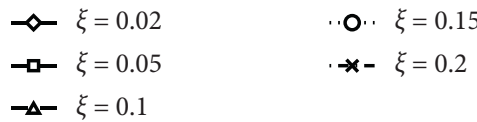

(a)

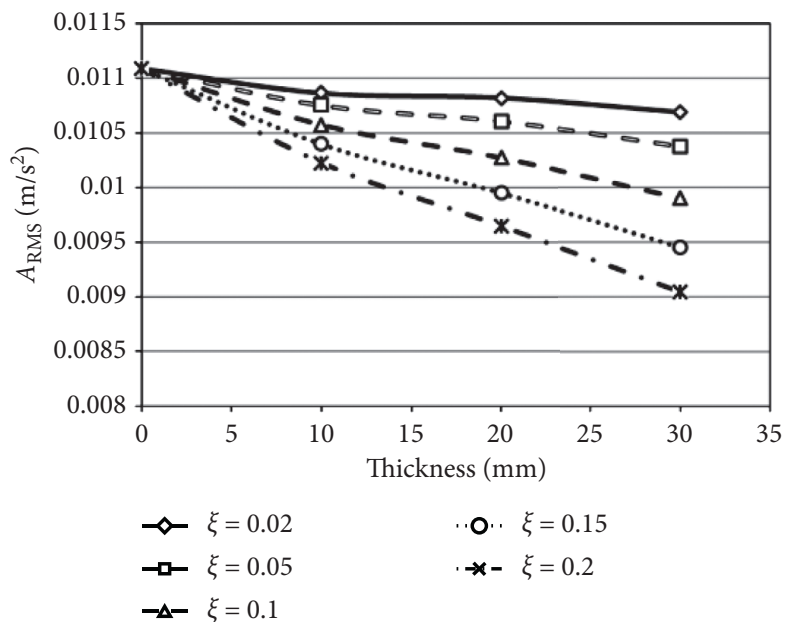

(c)

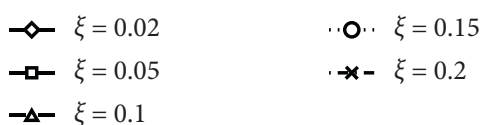

(b)

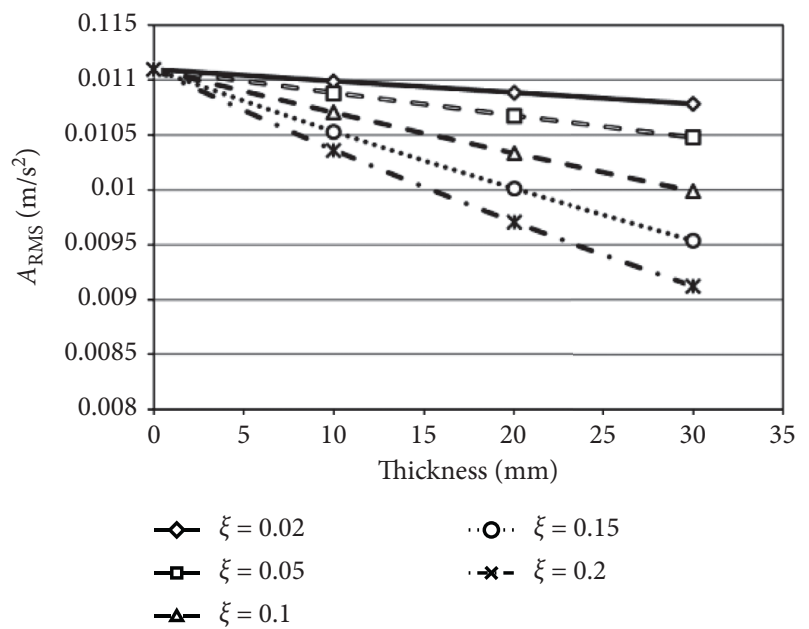

(d)

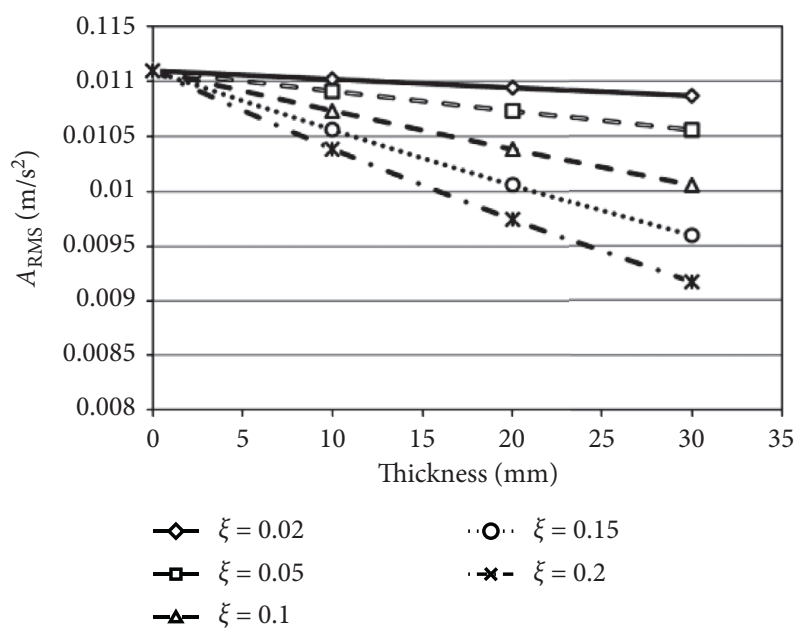

(e)

FIGURE 11: The effects of damping thickness at monitored point $\mathrm{E}$ (a) $0 \mathrm{~cm}$ from the top. (b) $5 \mathrm{~cm}$ from the top. (c) $10 \mathrm{~cm}$ from the top. (d) $15 \mathrm{~cm}$ from the top. (e) $20 \mathrm{~cm}$ from the top.

evaluated, as shown in Figure 12. The horizontal axis represents the damping layer position, which is the distance from the top.
The varying damping layer positions have a relatively obvious effect at point $\mathrm{E}$ compared to point $\mathrm{C}$ and point $\mathrm{A}$; at point $\mathrm{C}$, changing the position of the damping layer has 


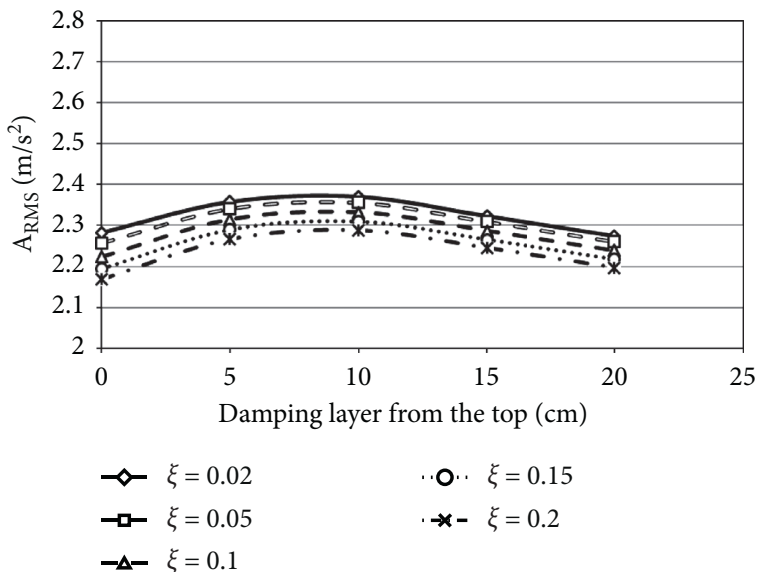

(a)

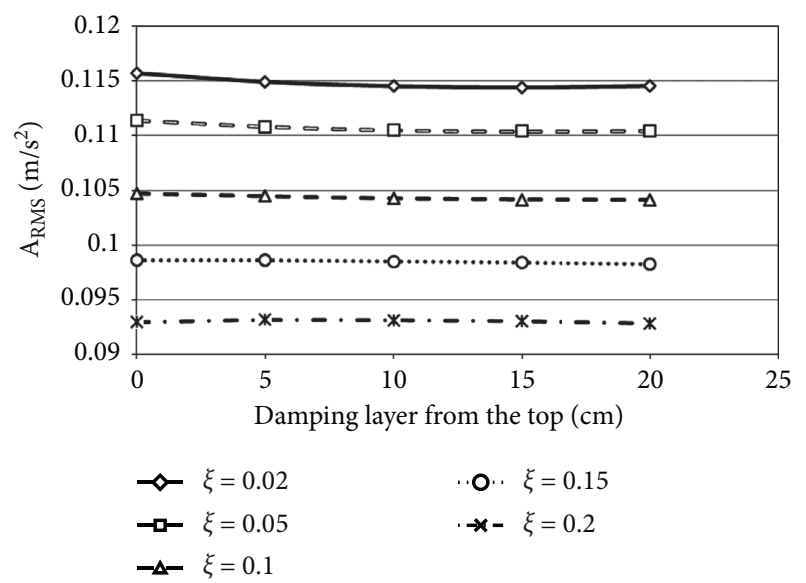

(b)

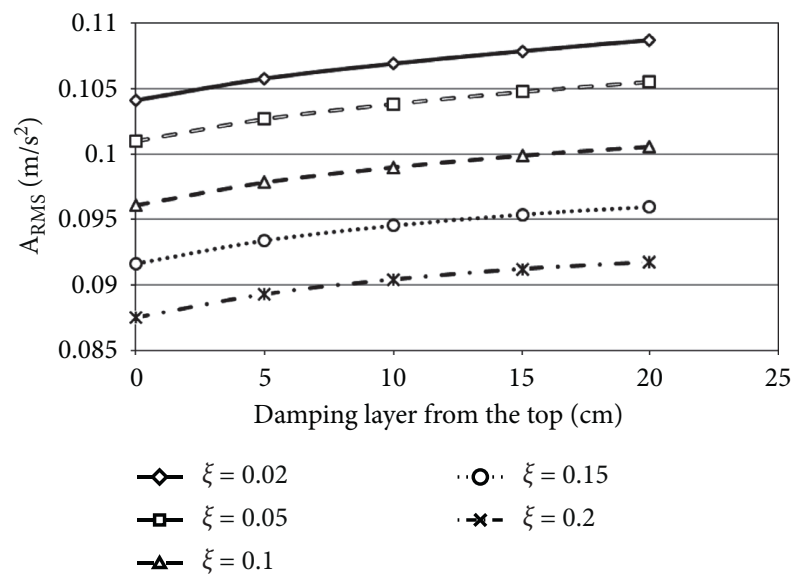

(c)

Figure 12: Effects of damping layer position on vibration reduction. (a) Point A. (b) Point C. (c) Point E.

almost no effect on the vibration response of the system. Hence, it can be concluded that the most meaningful point to select the optimized damping layer position is point $\mathrm{E}$, where the values of $A_{\mathrm{RMS}}$, the damping layer placed at the top, is the optimal position. However, due to the low indirect tensile strength (ITS) evaluated from the laboratory tests, the damping layer cannot work as a surface layer and the second choice might be the optimized position. Hence, it is determined that the optimized position for the damping layer can be $5 \mathrm{~cm}$ or $10 \mathrm{~cm}$ from the top.

\section{Conclusions}

To reduce traffic-induced vibrations on the slope stability of the open-pit mines, a novel antivibration trial pavement with a special damping layer was developed. To more fully examine the effectiveness of such a damping layer in the application and optimize the pavement structure, parametric studies based on a two-dimensional (2D) finite element (FE) model of the antivibration pavement were conducted. Sensitivity analysis of varying monitored points and varying loads are performed. Several important parameters such as the damping layer position and thickness, damping ratio are evaluated as well. By using this $\mathrm{FE}$ simulation to model the vibration response induced by traffic, some costly construction mistakes and field experimentation can be avoided. The conclusions from the simulations can be highlighted as follows:

(1) By laying a damping layer in the pavement structure, the obvious vibration reduction of $15 \%$ 20\% can be observed from $2 \mathrm{~m}$ to $30 \mathrm{~mm}$ away from the loading point, demonstrating the effectivity of the antivibration pavement on the slope stability of the open-pit mines. Therefore, it is practicable to construct the antivibration pavement with a special damping layer.

(2) For the loads with different loading times representing varying traffic-speed, the maximum vibration reductions can appear at different distances but show very similar trends, demonstrating the low sensitivity of the antivibration pavement on the traffic loads.

(3) With the increase of damping ratio, the RMS acceleration at the monitored point decreases linearity. In order to obtain the obvious vibration reduction 
effect to keep the slope stability, the damping ratio of the damping asphalt mixtures special for the damping layer should arrive at $0.15-0.2$, which is almost 2 times compared to the conventional rubberized mixture under the same loading condition, while from the laboratory results obtained, such design target can be realized.

(4) The increasing thickness of the damping layer does not necessarily reduce the vibration response at point A due to the low elastic modulus of damping asphalt mixtures, while considering the vibration reductions at monitored points $\mathrm{C}$ and $\mathrm{E}$, positive effects caused by the increased thickness can always be found. Also, the relationships between the vibration reduction and thickness are almost linear, from which the optimized thickness of the damping layer cannot be obtained directly. However, based on the construction cost and structure reliability, $30 \mathrm{~mm}$ can be the optimized thickness for the damping layer to keep the slope stability of open-pit mines.

(5) The effects of varying damping layer position at points $\mathrm{A}$ and $\mathrm{E}$ have a relatively bigger effect compared to point C. For the pavement structure referred to in the present study, the optimized position for the damping layer is $5 \mathrm{~cm}$ or $10 \mathrm{~cm}$ away from the top. In this way, the impact of traffic load on slope stability of the open-pit mines can be minimized.

Future developments will consider constructing a threedimensional (3D) FE simulation and evaluating the difference between the results obtained from the $3 \mathrm{D}$ models and the present study.

\section{Data Availability}

The experimental data used to support the findings of this study are available from the corresponding author upon request.

\section{Conflicts of Interest}

The authors declare that they have no conflicts of interest.

\section{Acknowledgments}

We gratefully acknowledge the funding from Surface Project of Natural Science Foundation of Jiangsu Province (grant no. BK20191340) and Independent Research Projects of State Key Laboratory of Coal Resources and Safe Mining, CUMT (SKLCRSM18X013).

\section{References}

[1] N. Haque, A. Hughes, S. Lim, and C. Vernon, "Rare earth elements: overview of mining, mineralogy, uses, sustainability and environmental impact," Resources, vol. 3, no. 4, pp. 614-635, 2014.

[2] J. R. Hein, K. Mizell, A. Koschinsky, and T. A. Conrad, "Deepocean mineral deposits as a source of critical metals for high- and green-technology applications: comparison with landbased resources," Ore Geology Reviews, vol. 51, pp. 1-14, 2013.

[3] J. Liu and J. C. Bongaerts, Mine Planning and Equipment Selection Supply Chain of Rare Earth Elements (REEs). Mine Planning and Equipment Selection, pp. 1419-1426, Springer, Berlin, Germany, 2014.

[4] A. Valero and A. Valero, "Physical geonomics: combining the exergy and Hubbert peak analysis for predicting mineral resources depletion," Resources, Conservation and Recycling, vol. 54, no. 12, pp. 1074-1083, 2010.

[5] D. Li and J. Zhang, "Rockburst monitoring in deep coalmines with protective coal panels using integrated microseismic and computed tomography methods," Shock and Vibration, vol. 2020, Article ID 8831351, 10 pages, 2020.

[6] J. Zhang, F. Jiang, S. Zhu, and L. Zhang, "Width design for gobs and isolated coal pillars based on overall burst-instability prevention in coal mines," Journal of Rock Mechanics and Geotechnical Engineering, vol. 8, no. 4, pp. 551-558, 2016.

[7] J. Zhang, Y. Wang, Y. Sun, and G. Li, "Strength of ensemble learning in multiclass classification of rockburst intensity," International Journal for Numerical and Analytical Methods in Geomechanics, vol. 44, no. 13, pp. 1833-1853, 2020.

[8] Y. Sun, G. Li, J. Zhang, and D. Qian, "Stability control for the rheological roadway by a novel high-efficiency jet grouting technique in deep underground coal mines," Sustainability, vol. 11, no. 22, p. 6494, 2019.

[9] Y. Sun, G. Li, J. Zhang et al., "Development of an ensemble intelligent model for assessing the strength of cemented paste backfill," Advances in Civil Engineering, vol. 2020, Article ID 1643529, 2020.

[10] Y. Sun, G. Li, N. Zhang et al., "Development of ensemble learning models to evaluate the strength of coal-grout materials," International Journal of Mining Science and Technology, 2020.

[11] Y. Sun, J. Zhang, G. Li et al., "Determination of Young's modulus of jet grouted coalcretes using an intelligent model," Engineering Geology, vol. 252, pp. 43-53, 2019.

[12] B. K. Diefenderfer and S. D. Link, Eds., "Temperature and confinement effects on the stiffness of a cold central-plant recycled mixture," Proceedings of the 12th international society for asphalt pavements conference on Asphalt pavements, Nagoya, Japan, August 2014.

[13] M. Monjezi, K. Shahriar, H. Dehghani, and F. Samimi Namin, "Environmental impact assessment of open pit mining in Iran," Environmental Geology, vol. 58, no. 1, pp. 205-216, 2009.

[14] D. R. Piteau and F. L. Peckover, "Engineering of rock slopes," Landslides Analysis and Control, vol. 176, pp. 192-228, Transportation Research Board, Washington, DC, USA, 1978.

[15] P. Stahl, B. Donmez, and G. Jamieson, Eds., "A field study of haul truck operations in open pit mines," Proceedings of the Human Factors and Ergonomics Society Annual Meeting, SAGE Publications Sage CA, Los Angeles, CA, USA, November 2011.

[16] Z. Bednarczyk, Ed., "Slope instabilities in polish open-pit mines," Landslides and Engineered Slopes. Experience, Theory and Practice: Proceedings of the 12th International Symposium on Landslides (Napoli, Italy, 12-une 2016), CRC Press, Boca Raton, FL, USA, 2018.

[17] A. Bo, Z. Chun, L. Kuiming et al., "The influence of rainfall on landslide stability of an open-pit mine: the case of haizhou open-pit mine," Geotechnical and Geological Engineering, vol. 37, no. 4, pp. 3367-3378, 2019. 
[18] M.-c. He, Z.-g. Tao, and B. Zhang, "Application of remote monitoring technology in landslides in the Luoshan mining area," Mining Science and Technology (China), vol. 19, no. 5, pp. 609-614, 2009.

[19] S. Jiang, M. Lian, C. Lu et al., "Ensemble prediction algorithm of anomaly monitoring based on big data analysis platform of open-pit mine slope," Complexity, vol. 2018, 2018.

[20] L. Nie, Z. Li, M. Zhang, and L. Xu, "Deformation characteristics and mechanism of the landslide in west open-pit mine, Fushun, China," Arabian Journal of Geosciences, vol. 8, no. 7, pp. 4457-4468, 2015.

[21] Z. Tao, Y. Shu, X. Yang et al., "Physical model test study on shear strength characteristics of slope sliding surface in Nanfen open-pit mine," International Journal of Mining Science and Technology, 2020.

[22] R. Wang and L. Nie, Eds., "Landslide prediction in Fushun west open pit mine area with quadratic curve exponential smoothing method," Proceedings of the 2010 18th International Conference on Geoinformatics, IEEE, Beijing, China, June 2010

[23] O. Hunaidi, Traffic Vibrations in Buildings, CiteSeer, Princeton, NJ, USA, 2000.

[24] L. Venturini, F. Giannattasio, and L. Sangalli, "Anti-vibration pavement: case of study Novara municipality," 2016.

[25] P. Clemente and D. Rinaldis, "Protection of a monumental building against traffic-induced vibrations," Soil Dynamics and Earthquake Engineering, vol. 17, no. 5, pp. 289-296, 1998.

[26] G. Dondi and A. Simone, Eds., "Soluzioni tecniche innovative per la mitigazione del rumore e delle vibrazioni da traffico stradale," Proceedings of the Atti della Conferenza Nazionale sulla politica energetica in Italia, Università di Bologna, Bologna, Italy, April 2005.

[27] F. Grandi, La progettazione di pavimentazioni antivibranti, ALMA, London, UK, 2008.

[28] T. Hanazato, K. Ugai, M. Mori, and R. Sakaguchi, "Threedimensional analysis of traffic-induced ground vibrations," Journal of Geotechnical Engineering, vol. 117, no. 8, pp. 1133-1151, 1991.

[29] S. County, Report on the Status of Rubberized Asphalt Traffic Noise Reduction in Sacramento County, Sacramento County and Bollard \& Brennan Inc, Sacramento County, CA, USA, 1999.

[30] A. Y. Aköz, F. Kadıoğlu, and G. Tekin, "Quasi-static and dynamic analysis of viscoelastic plates," Mechanics of TimeDependent Materials, vol. 19, no. 4, pp. 483-503, 2015.

[31] I. L. Al-Qadi, H. Wang, P. J. Yoo, and S. H. Dessouky, "Dynamic analysis and in situ validation of perpetual pavement response to vehicular loading," Transportation Research Record: Journal of the Transportation Research Board, vol. 2087, no. 1, pp. 29-39, 2008.

[32] M. Ameri, M. Malakouti, and P. Malekzadeh, "Quasi-static analysis of multilayered domains with viscoelastic layer using incremental-layerwise finite element method," Mechanics of Time-Dependent Materials, vol. 18, no. 1, pp. 275-291, 2014.

[33] K. Chatti, Y. Ji, and R. Harichandran, "Dynamic time domain backcalculation of layer moduli, damping, and thicknesses in flexible pavements," Transportation Research Record: Journal of the Transportation Research Board, vol. 1869, no. 1, pp. 106-116, 2004.

[34] I. Chowdhury and S. P. Dasgupta, "Computation of Rayleigh damping coefficients for large systems," The Electronic Journal of Geotechnical Engineering, vol. 8, no. 0, pp. 1-11, 2003.

[35] J. Huang, M. Losa, and P. Leandri, Eds., in in Proceedings of the Conference of the Advances in Materials and Pavement
Performance Prediction (AM3P 2018), CRC Press, Doha, Qatar, April 2018.

[36] J. Huang, R. Alyousef, M. Suhatril et al., "Influence of porosity and cement grade on concrete mechanical properties," Advances in Concrete Construction, vol. 10, no. 5, pp. 393-402, 2020.

[37] J. Huang and Y. Sun, "Effect of modifiers on the rutting, moisture-induced damage, and workability properties of hot mix asphalt mixtures," Applied Sciences, vol. 10, no. 20, p. $7145,2020$.

[38] J. Huang and Y. Sun, "Viscoelastic analysis of the damping asphalt mixtures (DAMs) made with a high content of asphalt rubber (AR)," Advances in Civil Engineering, vol. 2020, Article ID 8826926, 12 pages, 2020. 